\title{
Decrement in distress to an aversive event during a conditioned positive opponent-process
}

\author{
JOSEPH D. LaBARBERA and WILLIAM F. CAUL \\ Vanderbilt University, Nashville, Tennessee 37240
}

\begin{abstract}
During Phase 1, 24 rats received $\mathrm{CS}_{1}$ (light)-shock trials while the remaining 24 rats received $\mathrm{CS}_{1}$ and shock on a random control schedule. During Phase 2, all subjects were presented trials of $\mathrm{CS}_{2}$ (tone)-shock. When $\mathrm{CS}_{2}$ was subsequently presented immediately after $\mathrm{CS}_{1}$ while subjects licked for water, it was found that subjects that had received $\mathrm{CS}_{1}$-shock pairings during Phase 1 exhibited less suppression of licking to $\mathrm{CS}_{2}$, indicating less distress, than control subjects. The results are compatible with the opponent-process theory and suggest the presence of a positive hedonic afterreaction to an aversive event which reduced distress to a following aversive event.
\end{abstract}

Can the delivery of an aversive event reduce the magnitude of distress experienced by a rat in reaction to a subsequent aversive event? Solomon and Corbit's (1974) opponent-process theory of motivation implies that a hedonically positive aftereffect aroused by an aversive event should reduce the distress elicited by an aversive event that immediately follows. The theory holds that a hedonically positive b-process, as well as a negative a-process, is activated during the presentation of an aversive event. However, the b-process is sluggish in nature: it appears after the arousal of the a-process and decays after the aversive stimulus and the a-process have terminated. Therefore, if the positive hedonic effect that remains after the termination of the aversive event is temporally superimposed upon a following aversive event, the magnitude of distress elicited by that second event should be diminished.

Solomon and Corbit hypothesize further that repeated presentations of the same aversive event have no effect upon the negative a-process. However, after many presentations, the positive b-process is strengthened in intensity. Consequently, during stimulus onset, the strengthened b-process serves to diminish the effects of the a-process. When the stimulus and the a-process are terminated, the strengthened b-process is apparent in terms of behavior that is motivationally more intense that before. The theory predicts, therefore, that after repeated delivery of an aversive event, its capacity to reduce distress to a subsequent aversive event should increase.

Preliminary data from our laboratory suggest that a positive afterreaction to an aversive event can

A version of this report was presented at the annual meeting of the Southeastern Psychological Association, New Orleans, Louisiana, March 1976. Requests for reprints should be sent to J. D. LaBarbera, Department of Psychology, Vanderbilt University, Nashville, Tennessee 37240. indeed reduce distress to a following aversive event. During Phase 1, all 48 water-deprived rats received Pavlovian conditioning trials of a $5.5-\mathrm{sec}$ light $\mathrm{CS}_{1}$ which coterminated with a .75-mA shock US of .5 sec duration. During Phase 2, on the following day, conditioning trials consisted of the light $\mathrm{CS}_{1}$ whose termination coincided with the onset of a $\mathrm{CS}_{2}$-shock pairing for half the subjects. The remaining subjects were presented trials of $\mathrm{CS}_{2}$-shock alone. The $\mathrm{CS}_{2}$ was a 70-dB tone of $2.5 \mathrm{sec}$ duration, and the shock was identical to that delivered during Phase 1. During Phase 3, $\mathrm{CS}_{2}$-was presented under extinction conditions while a subject licked for water. Subjects that had received $\mathrm{CS}_{1}-\mathrm{CS}_{2}$-shock showed less suppression of licking, implying less distress, than did $\mathrm{CS}_{2}$-shock subjects. The effect was apparent through seven testing sessions.

These results are compatible with the opponent process theory. When $\mathrm{CS}_{1}$, which was paired with a shock US, was terminated, a B-state of positive affective value remained. Then, when $\mathrm{CS}_{2}$-shock was presented in the immediate aftermath of $\mathrm{CS}_{1}$, the negative primary affective reaction, or A-state, to $\mathrm{CS}_{2}$-shock was superimposed on the positive B-state of $\mathrm{CS}_{1}$. Subjects that received only $\mathrm{CS}_{2}$-shock, however, experienced a negative A-state in the absence of an overlapping positive B-state. For $\mathrm{CS}_{1}-\mathrm{CS}_{2}$-shock subjects, the positive aftereffects of $\mathrm{CS}_{1}$ offset some of the negative effects of $\mathrm{CS}_{2}$-shock, resulting in an overall decrement distress to $\mathrm{CS}_{2}$ shock and, consequently, less suppression of licking in the $\mathrm{CS}_{2}$ test situation, relative to $\mathrm{CS}_{2}$-shock subjects.

However, two competing explanations could also apply. It may be that the excitatory associative properties of $\mathrm{CS}_{1}$ blocked an association of $\mathrm{CS}_{2}$ to shock (e.g., Rescorla \& Wagner, 1972) for experimental subjects, thereby accounting for less distress elicited by $\mathrm{CS}_{2}$ during testing. Alternatively, the temporal priority of $\mathrm{CS}_{1}$, regardless of its theoretical 
properties, may have been sufficient to impair an association between $\mathrm{CS}_{2}$ and shock.

The present study sought to replicate this preliminary finding that the delivery of a prior aversive event can reduce distress to the next event. An additional purpose was to evaluate the applicability of the opponent-process theory to the data, while employing a design that ruled out the aforementioned alternative interpretations. It should be noted that the current study extends the opponent-process theory from single aversive events to a situation involving successive aversive events.

\section{Subjects \\ METHOD \\ The subjects were 48 experimentally naive male Holtzman rats. The mean age was 101 days and the mean weight was $307 \mathrm{~g}$ at the beginning of the study.}

\begin{abstract}
Apparatus
Two experimental chambers that were functionally equivalent were employed. The first was a circular Plexiglas runway constructed to resemble that described by Anisman and Waller (1972). The runway was $12.0 \mathrm{~cm}$ wide, $20.5 \mathrm{~cm}$ high, with an outside circumference of $204.1 \mathrm{~cm}$. A speaker, capable of emitting an $80-\mathrm{dB}, 1-\mathrm{kHz}$ tone as well as $70-\mathrm{dB}$ white noise was located above the runway. Slots in the exterior wall permitted the insertion of black bristol-board sheets. The alley was divided equally into four compartments by Plexiglas guillotine gates. The alley had a grid floor of 0.25 -cm stainless steel rods spaced $1.75 \mathrm{~cm}$ apart (center to center) at the exterior wall. Situated on either side of the gate was a $7.5-W$ lamp located $2.5 \mathrm{~cm}$ beneath the Plexiglas roof. The second apparatus was a duplicate of one of the four compartments of the apparatus described above. It had curved sides, $51.2 \mathrm{~cm}$ long on one side and $32.2 \mathrm{~cm}$ long on the other. Scrambled shock was delivered to each chamber from separate shock generators.

In addition, a lick box similar to that described by Caul and Barrett (1972) was used. The box was $25.0 \mathrm{~cm}$ deep, $20.0 \mathrm{~cm}$ high, with a grid floor. The wall was fitted with a drinking tube of the sort used for watering the animals in their home cages. Lick responses were monitored by a Grason-Stadler Drinkometer (Model E4690A-2) and recorded on electromechanical counters.
\end{abstract}

\section{Procedure}

All 48 subjects were partially deprived of water for the duration of the experiment, beginning 10 days prior to Phase 1 . During the first 5 of these days, the subjects had access to unlimited water in their home cages for one 20 -min period each day. From the 6th day to the end of the study, the subjects received water for $10 \mathrm{~min}$ in their home cages. During these days, prior to receiving water in their home cages, each subject was placed in the lick box for $10 \mathrm{~min}$, or until 1,000 licks were recorded.

Phase 1 lasted for two sessions and was introduced after five sessions of lick training. Subjects were taken in pairs from their home cages. One subject was placed in the single-compartment apparatus, while the other was placed in a chamber of the circular apparatus. Twenty-four of the subjects received trials consisting of a light $\mathrm{CS}_{1}$ for $6.5 \mathrm{sec}$ coterminating with a $.75-\mathrm{mA}$ scrambled shock of $.5 \mathrm{sec}$ duration. The remaining 24 subjects received equal numbers of $\mathrm{CS}_{1}$ and shock but on independent variable-time schedules such that the presentation of $\mathrm{CS}_{1}$ predicted neither the occurrence nor the absence of shock (Rescorla, 1967). For both groups of subjects, shock was delivered on a variable-time 1 -min schedule in which intertrial intervals ranged from 1 to $120 \mathrm{sec}$. During Phase 1, the subjects in the two treatment groups received either 2, 20, or 200 trials; one-half the required number of trials were presented during each of the two sessions. After a pair of subjects received the appropriate number of Phase 1 conditioning trials, they were alternately placed in the lick box for $10 \mathrm{~min}$ or until a subject had licked for water 1,000 times.

Phase 2 was presented on the following day. A pair of subjects was again taken from their home cages and one was placed in each experimental chamber. All subjects received four $\mathrm{CS}_{2}$-shock Pavlovian conditioning trials. $\mathrm{CS}_{2}$ was a 6.5 -sec tone which coterminated with a .75 -mA scrambled shock of $.5 \mathrm{sec}$ duration. Trials were delivered on a variable-time 1-min schedule. After receiving the conditioning trials, a subject was placed in the lick box for $10 \mathrm{~min}$ or until it had licked 1,000 times.

Phase 3 comprised the following 10 days. A subject was placed in the lick box and the elapsed time to 200 licks was noted. Commencing with the 200th lick, lick rates were monitored during three successive 6-sec intervals. While no CS was present during the first interval, $\mathrm{CS}_{1}$ occurred during the second interval and was immediately followed by $\mathrm{CS}_{2}$ during the third interval.

\section{RESULTS}

Initial analyses indicated that baseline licking rates during Phase 3 did not differ among the experimental groups. A 2 (Phase 1 Treatment) by 3 (Phase 1 Trials) by 10 (Testing Days) analysis of variance was used to evaluate the elapsed time to 200 licks. The analysis showed a significant Testing Days main effect, $\mathrm{F}(9,378)=3.82, \mathrm{p}<.001$, indicating that baseline licking rates for all subjects increased with days. All remaining main effects and interactions were nonsignificant. In addition, a 2 by 3 by 10 analysis of variance of lick responding during the 6-sec pre-CS interval showed no significant main effects or interactions.

The number of lick responses during $\mathrm{CS}_{1}$ was also investigated by a 2 by 3 by 10 analysis which indicated a significant Testing Days main effect, showing that licking increased in frequency over days, $F(9,378)=$ $11.33, \mathrm{p}<.001$. The remaining main effects and interactions were nonsignificant. In particular, the Phase 1 Treatment main effect implied that subjects that had received $C_{1}$-shock pairings $(\bar{X}=2.27)$ did not emit fewer licks during $\mathrm{CS}_{1}$ than did subjects that received $\mathrm{CS}_{1}$ and shock on a random control schedule $(\overline{\mathrm{X}}=5.99)$, although this effect approached significance, $F(1,42)=3.51, p=.06$.

Figure 1 shows that subjects that had received $\mathrm{CS}_{1}$-shock pairings during Phase $1(\overline{\mathrm{X}}=13.15)$ consistently emitted more licks in the presence of $\mathrm{CS}_{2}$ during testing than did control subjects $\overline{\bar{X}}=5.86$ ). This result is apparent for each of the three groups of subjects that were defined by the number of Phase 1 trials. A 2 by 3 by 10 analysis of variance demonstrated that this main effect of Phase 1 Treatment was significant, $F(1,42)=4.81, \mathrm{p}<.05$.

It can also be observed from Figure 1 that the frequency of licking during $\mathrm{CS}_{2}$ increased with days of testing, $F(9,378)=27.40, p<.001$. The Phase 1 Treatment by Phase 1 Trials interaction was non- 


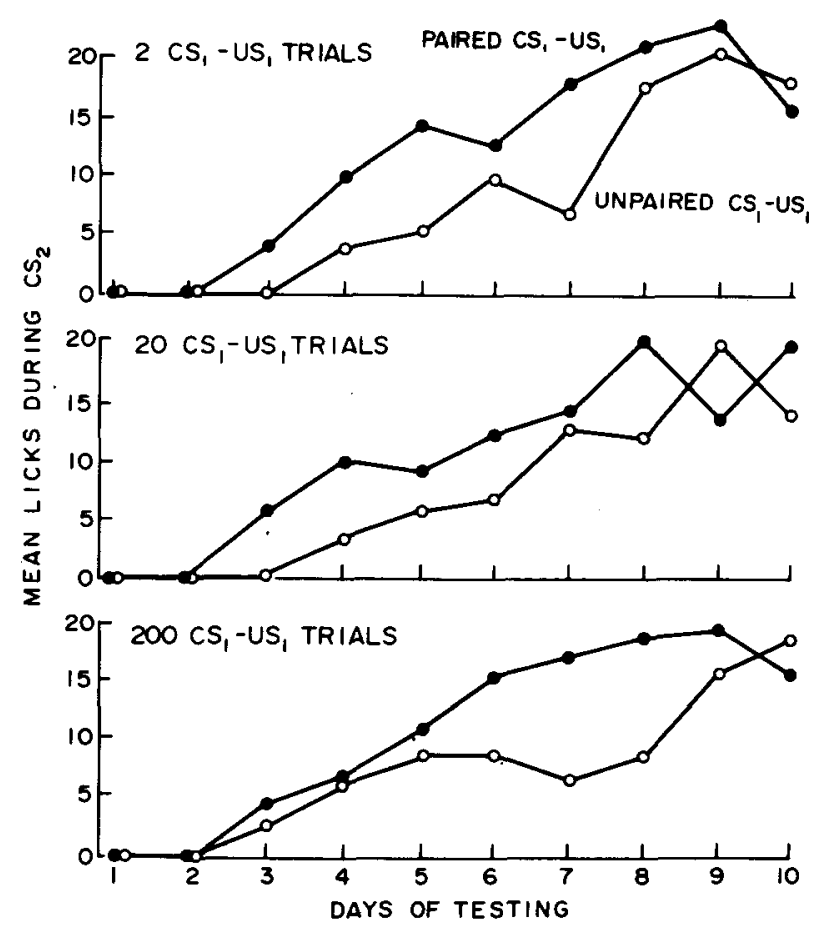

Figure 1. Mean responses emitted during $\operatorname{CS}_{2}$ for subjects that received $C S_{1}$-shocks pairings and $C S_{1}$ and shock on a random control schedule, shown as a function of days of testing. Data are presented for the three groups of subjects defined by the number of conditioning trials during Phase 1.

significant, indicating that the differential frequency of licking during $\mathrm{CS}_{2}$ for the two treatment groups did not increase as a function of trials during Phase 1 . The remaining factors in the analysis were nonsignificant.

\section{DISCUSSION}

One can conclude from these results that the magnitude of distress exhibited by a rat in response to an aversive CS may be reduced when preceded by another aversive CS. During testing, all subjects received $\mathrm{CS}_{1}$ followed by $\mathrm{CS}_{2}$ while licking for water. Subjects for which $\mathrm{CS}_{1}$ had reliably signaled shock during Phase 1 showed a greater number of licks during $\mathrm{CS}_{2}$ than did subjects for which $\mathrm{CS}_{1}$ did not reliably signal shock during Phase 1 . This result was apparent for all three groups of subjects defined by the number of Pavlovian conditioning trials during Phase 1. Therefore, subjects for which CS $_{1}$ should have acquired aversive motivational properties exhibited more licks during $\mathrm{CS}_{2}$ than did those for which $C_{1}$ presumably acquired little or no aversive conditioning. Since James and Mostoway (1968) have demonstrated that acquisition of conditioned suppression of licking tends to vary with the intensity of shock and, by inference, with the magnitude of distress to shock, these data imply that the magnitude of distress elicited by an aversive CS was diminished when preceded by another aversive CS.

While the results seem unambiguous, several theoretical explanations might be proposed for them. Conceivably, experimental subjects licked more than controls in the presence of $\mathrm{CS}_{\mathbf{2}}$ because their attention to $\mathrm{CS}_{1}$ implied a decrement in attention to $\mathrm{CS}_{2}$, such that $\mathrm{CS}_{2}$ elicited less distress. While this explanation is not specifically ruled out by this study, Mackintosh (1975) has argued, in developing a theory of attention, that this "inverse hypothesis" is not generally justified, even for stimuli that are presented concurrently. He notes that: "it stretches credulity to suppose that the rat's channel capacity is too limited to permit processing of both a loud tone and a bright light"' (p. 281). Furthermore, he holds that the experimental data that have occasionally been explained by way of, and therefore justified the existence of, the inverse hypothesis, e.g., blocking and overshadowing, may be more appropriately interpreted in terms of a subject's learning to ignore redundant stimuli, and not by accounts of selective attention.

Alternatively, one might propose that experimental subjects showed less distress in the presence of $\mathrm{CS}_{2}$ because $\mathrm{CS}_{2}$ served as the best predictor of the absence of shock after $\mathrm{CS}_{1}$. The safety-signaling properties of $\mathrm{CS}_{2}$ may have reduced its capacity to elicit distress for experimental subjects, thereby yielding a higher rate of responding in the presence of $\mathrm{CS}_{2}$. Much of the strength of this notion comes from a study by Rescorla and LoLordo (1965). Dogs received Pavlovian conditioning trials of $\mathrm{CS}_{1}$-shock interspersed with $\mathrm{CS}_{1}-\mathrm{CS}_{2}$ (and no shock), and $\mathrm{CS}_{2}$ subsequently inhibited fear in the sense of reducing the ongoing rate of unsignaled avoidance responding. However, generalizing the findings of Rescorla and LoLordo to the present data would seem to be limited by two procedural differences between the two studies. First, while $\mathrm{CS}_{2}$ in their study was neutral before being delivered subsequent to $\mathrm{CS}_{1}$, in the present case it had previously been paired with shock during Phase 2 and therefore should have acquired aversive properties. An explanation of these data in terms of the analysis derived from the Rescorla and LoLordo data implies that a danger signal $\left(\mathrm{CS}_{2}\right)$ could have actually forecast safety for experimental subjects, and this seems to us unlikely. Second, the schedule of conditioning trials in the Rescorla and LoLordo study clearly provided the conditions necessary for the development of $\mathrm{CS}_{2}$ as a predictor of no-shock, since $\mathrm{CS}_{2}$ reliably signaled a 1-min minimum intertrial interval of safety (LoLordo, 1969). In contrast, since $\mathrm{CS}_{1}$-shock trials during Phase 1 of the present study were delivered on a schedule with intertrial intervals varying from 1 to $120 \mathrm{sec}$, the addition of $\mathrm{CS}_{2}$ during testing 
cannot be said to have reliably signaled a period of time free from forthcoming shock.

While the foregoing reasoning suggests that the present study is not readily explained in terms of inhibition of fear accruing to $\mathrm{CS}_{2}$ for experimental subjects, it may be necessary to explore this explanation in more formal terms. Rescorla and Wagner (1972) have proposed a model to describe the theoretical change in conditioning as a result of reinforcement or nonreinforcement to a stimulus that is presented in compound with other stimuli. Briefly, the theory posits that simultaneously presented stimuli compete for the excitatory or inhibitory strength available from a specific reinforcement or nonreinforcement. Their equation requires that a stimulus will be reduced in associative strength as a function of the excitatory strength of a second stimulus also present when the compound is nonreinforced. It can be shown that the theory predicts the inhibitory association of $\mathrm{CS}_{\mathbf{2}}$ in the Rescorla and LoLordo study when that situation is considered as an instance of a negative correlation between $\mathrm{CS}_{2}$ and shock. In this case, the rate of shock in the presence of background stimuli (B) must be said to affect the amount of conditioning of an intermingled pairing of $\mathrm{CS}_{2}$ and $\mathrm{B}$ (Rescorla, 1972). Assuming that the asymptote of conditioning supportable by nonreinforcement is zero, then an initially neutral $\mathrm{CS}_{2}$ becomes inhibitory when the $\mathrm{CS}_{2} \mathrm{~B}$ compound is nonreinforced, i.e., $\Delta \mathrm{V}_{\mathrm{CS}_{2}}=$ $\alpha \beta\left[0-\left(V_{C_{2}}+V_{B}\right)\right]$ is negative when $B$ is positive.

Rescorla and Wagner's theory does not predict a greater reduction in excitatory strength during $\mathrm{CS}_{2}$ for experimental subjects over controls in the present study. If we assume the presence after $\mathrm{CS}_{\mathbf{1}}$ of more highly excitatory background stimuli for experimental subjects than for controls, then the model predicts a greater decrement in associatve strength to $\mathrm{CS}_{2}$ taken in isolation for experimental subjects, but at the same time an overall greater excitatory value for the $\mathrm{CS}_{2} \mathrm{~B}$ compound for these subjects. Since it must also be assumed that subjects respond to both components of the $\mathrm{CS}_{2} \mathrm{~B}$ compound during the onset of $\mathrm{CS}_{2}$ (if they do not respond to $\mathrm{B}$, there is no rationale for expecting blocking of $\mathrm{CS}_{2}$ and also no prediction of less associative strength during $\mathrm{CS}_{2}$ ), then we would expect not less distress but, in fact, greater overall distress when $\mathrm{CS}_{2}$ is presented to experimental subjects. That is, while $\Delta \mathrm{V}_{\mathrm{CS}_{2}}=\alpha \beta[0-$ $\left(\mathrm{V}_{\mathrm{CS}_{2}}+\mathrm{V}_{\mathrm{B}}\right)$ ] for experimental subjects is a more accelerated negative function than is $\Delta \mathrm{V}_{\mathrm{CS}_{2}}=\alpha \beta[0-$ $\left.\left(V_{C_{2}}+V_{B}\right)\right]$ for controls, the excitatory strength for the compound $\left(\mathrm{V}_{\mathrm{CS}_{2} \mathrm{~B}}\right)$ for experimentals is at all times greater than that for controls. The upshot, then, is that the model predicts more distress during $\mathrm{CS}_{2}$ for experimental subjects and not the obtained results of less distress.

If Rescorla and Wagner's model, with its implicit assumption that stimuli compete for inhibitory strength during extinction, does not predict the obtained data, then one might consider the opposite argument-that extinction to one CS can increase the ongoing rate of extinction to another CS. This notion, when applied to the present finding of less distress to $\mathrm{CS}_{2}$ for subjects that received $\mathrm{CS}_{1}$-US pairings during Phase 1, implies that extinction to $\mathrm{CS}_{2}$ was accelerated by the simultaneously occurring extinction to the excitatory $\mathrm{CS}_{1}$. In contrast, subjects that received unpaired presentations of $\mathrm{CS}_{1}$ and US during Phase 1, and for which $\mathrm{CS}_{1}$ acquired little or no excitatory value, extinguished to $\mathrm{CS}_{2}$ alone during testing. Thus, such an explanation would hold that experimental subjects extinguished to $\mathrm{CS}_{2}$ faster than controls because the concurrent extinction to $\mathrm{CS}_{1}$ in some manner generalized to $\mathrm{CS}_{2}$. It should be noted, however, that while this view seems plausible and merits experimental study, no relevant supporting data exist.

It may be appropriate to assume that the prior presentation of a distress-eliciting $\mathrm{CS}_{1}$ in some manner reduced the magnitude of distress elicited by $\mathrm{CS}_{2}$. An opponent-process interpretation of these data holds that a positive hedonic state was present after the termination of $\mathrm{CS}_{1}$. This positive B-state, in turn, lessened the aversiveness of $\mathrm{CS}_{2}$, upon which it was superimposed. Consequently, the results may indicate that the hedonic aftereffect of an aversive CS can reduce distress to an aversive CS that immediately follows. The results also appear to demonstrate that when two successive aversive events are presented to a subject, the valence and intensity of the negative primary effective reaction experienced by a subject during the second event is a combination of the positive B-state of the first event and the negative A-state of the second event. This finding provides a step toward clarifying the ways in which $A$ and $B$ states associated with different motivating events may interact. If this interpretation is correct, the results would also increase the applicability of the opponent process theory from single motivational stimuli to more complex situations involving two successively presented aversive stimuli.

Solomon and Corbit note that the theory "would encompass an even larger array of data on acquired emotion if it could be safely assumed that A states, or B states, or both could be brought under the control of previously neutral stimuli as a consequence of experience"' (p. 133). The necessary criterion for assuming the association of a neutral stimulus and a negative $A$ state is evidence of a positive $B$ state upon termination of the CS. If one can infer such a biphasic recovery to the aversive $\mathrm{CS}_{1}$ in the present study, then the putative positive aftereffect of $\mathrm{CS}_{1}$ termination served to reduce the distress to the concurrent aversive event.

The opponent-process theory holds that a positive 
B-state should increase with repeated presentations of the same aversive event. We have previously reported data showing that postshock inhibition of fear did indeed increase as a function of trials (LaBarbera \& Caul, 1976). However, for reasons that are not clear, this effect was not noted in the present study where subjects failed to exhibit less distress during $\mathrm{CS}_{2}$ as a function of the number of $\mathrm{CS}_{1}$-shock trials during Phase 1 . One possibility is that a B-state increases in strength only when occurring in reaction to an aversive event in unconditioned form.

\section{REFERENCES}

ANisman, H., \& WALLER, T. G. Facilitative and disruptive effects of prior exposure to shock on subsequent avoidance performance. Journal of Comparative and Physiological Psychology, 1972, 78, 113-122.

CaUl, W. F., \& Barrett, R. J. Electroconvulsive shock effects on conditioned heart rate and suppression of drinking. Physiology and Behavior, 1972, 8, 287-290.

James, J. P., \& MostowaY, W. W. Conditioned suppression of licking as a function of shock intensity. Psychonomic Science, $1968,13,161-162$.
LABarbera, J. D., \& CAUL, W. F. An opponent-process interpretation of post-shock bursts in appetitive responding. Animal Learning \& Behavior, 1976, 4, 386-390.

LoLordo, V. M. Positive conditioned reinforcement from aversive situations. Psychological Bulletin, 1969, 72, 193-203.

Mackintosh, N. J. A theory of attention: Variations in the associability of stimuli with reinforcement. Psychological Review, 1975, 82, 276-298.

RESCORLA, R. A. Information variables in Pavlovian conditioning. In G. Bower (Ed.), The psychology of learning and motivation (Vol. 6). New York: Academic Press, 1972.

Rescorla, R. A. Pavlovian conditioning and its proper control procedures. Psychological Review, 1967, 74, 71-80.

ResCORLA, R. A., \& LoLoRdo, V. M. Inhibition of avoidance behavior. Joumal of Comparative and Physiological Psychology, $1965,69,406-412$.

Rescorla, R. A., \& WAgner, A. R. A theory of Pavlovian conditioning: Variations in the effectiveness of reinforcement and non-reinforcement. In A. H. Black \& W. F. Prokasy (Eds.), Classical conditioning II: Current theory and research. New York: Appleton-Century-Crofts, 1972.

Solomon, R. L., \& Corirt, J. D. An opponent-process theory of motivation: I. Temporal dynamics of affect. Psychological Review, 1974, 81, 119-145.

(Received for publication June 2, 1975; revision accepted August 31, 1976.) 